\title{
Uso del herbicida glifosato en Costa Rica en el periodo 2007 a 2015
}

\section{Use of the Herbicide Glyphosate in Costa Rica Between 2007-2015}

\author{
Fernando Ramírez-Muñoz \\ fernando.ramirez.munoz@una.cr \\ Instituto Regional de Estudios en Sustancias Tóxicas \\ Universidad Nacional, Costa Rica \\ Virya Bravo-Durán \\ virya.bravo.duran@una.cr \\ Instituto Regional de Estudios en Sustancias Tóxicas \\ Universidad Nacional, Costa Rica \\ Gustavo Herrera-Ledezma \\ gustavohledezma@hotmail.com \\ Instituto Regional de Estudios en Sustancias Tóxicas \\ Universidad Nacional, Costa Rica
}

Recibido-Received: 13/feb/2015 / Corregido-Corrected: 26/abril /2015.

Aceptado-Accepted: 28/set/2015 / Publicado-Published: 31/ene /2017.

\begin{abstract}
Resumen
Costa Rica es uno de los mayores importadores y usuarios de plaguicidas a nivel centroamericano. El glifosato es el herbicida de mayor uso, tanto en el mundo como en Costa Rica. Se utiliza en la mayoría de cultivos: anuales, perennes y en zonas no agrícolas. Por medio de entrevistas a sujetos productores agrícolas se conocieron las cantidades usadas de glifosato en los principales cultivos. Las importaciones de este herbicida se iniciaron en 1982 con 36 toneladas de ingrediente activo ( $\mathrm{T}$ i.a.), y se llegó a importar $1761 \mathrm{~T}$ i.a. en 2013. Se calculó el uso ponderado de glifosato en kg i.a./ ha/ciclo. Los cultivos perennes son los principales consumidores de glifosato (51,6\% del total), le siguen las zonas no agrícolas $(37,1 \%)$ y los cultivos anuales (10,8\%), la mayoría granos como arroz, frijol y maíz. Por cultivo, la palma africana consume el $24,9 \%$ del total de glifosato usado en el país, le sigue el arroz (7,8\%), café $(5,4 \%)$, banano (5,2\%), cítricos $(4,6 \%)$ y pastos $(3,7 \%)$. En cultivos como el pejibaye para palmito, se nota una dependencia de este herbicida en el manejo de malezas, lo que ha llevado a que poblaciones de malezas evolucionen en resistencia.
\end{abstract}

Palabras claves: Herbicidas; uso de plaguicidas; cultivos; manejo malezas.

\begin{abstract}
Costa Rica is one of the largest importers and users of pesticides in Central America. Glyphosate is the most widely used herbicide worldwide as in Costa Rica. It is used in most crops, both annual and perennial and in non-agricultural areas. The glyphosate amounts used on major crops in Costa Rica became known through interviews with farmers. Costa Rica started importing this herbicide in 1982 with 36 tons of active ingredient ( $\mathrm{T}$ ai) reaching in 2013 the amount of 1,761 $\mathrm{T}$ ia. The weighted average use of glyphosate in $\mathrm{kg}$ ai / ha / cycle was calculated. The perennial crops are the
\end{abstract}


UNICIENCIA Vol. 31, No. 1, pp. 59-72. Enero-junio, 2017.

ISSN Electrónico: 2215-3470

URL: www.revistas.una.ac.cr/uniciencia

DOI: $\underline{\text { http://dx.doi.org/10.15359/ru.31-1.7 }}$

Email: revistauniciencia@una.cr

main consumers of glyphosate (51.6\% of the total), followed by non-agricultural areas (37.1\%) and annual crops (10.8\%) most grains like rice, beans and corn. By culture, African palm consume $24.9 \%$ of glyphosate used in the country, followed by rice $(7.8 \%)$, coffee $(5.4 \%)$, bananas $(5.2 \%)$, citrus fruits $(4.6 \%)$ and pastures $(3.7 \%)$. In some crops, such as hearth-palm trees, a dependency on this herbicide in weed management has led resistant weed populations to evolve.

Keywords: herbicides, pesticide use, crops, weed management.

La agricultura en Costa Rica es altamente dependiente de los plaguicidas. A nivel centroamericano, nuestro país se ubicó, para el quinquenio 2005-2009, como el mayor importador de plaguicidas por habitante, habitante rural, trabajador agrícola y superficie agropecuaria ( $\underline{B r a v o}$ et al., 2015). La Agencia para la Agricultura y la Alimentación (FAO) de las Naciones Unidas (FAOSTAT, 2015) reporta para Costa Rica un consumo de plaguicidas para el año 2010 de 24,6 $\mathrm{Kg}$ i.a./ha/año, uno de los mayores a nivel mundial. Y datos oficiales del Servicio Fitosanitario del Estado (SFE, 2015) lo colocan en 15,5 para el mismo año. Los herbicidas históricamente se han constituido en Costa Rica en el segundo grupo más importado, representando casi un 30\% de la importación anual, solamente superados por los fungicidas, con el 45\% (Ramírez et al., 2009). El glifosato, desde su primera importación en 1982 (36 T i.a.) hasta el 2013 (1 761 T i.a.), incrementó 48,5 veces la cantidad importada y hoy es el segundo i.a. más importado en Costa Rica, representando el $10,5 \%$ de la cantidad total importada de plaguicidas y el $33,6 \%$ de los herbicidas en el periodo 2006 a 2010 (Ramírez et al., 2014a).

El glifosato (N-[fosfonometil] glicina) es un herbicida de aplicación foliar postemergente y de acción total, ampliamente usado para el control no selectivo de plantas herbáceas y leñosas. La molécula fue inicialmente sintetizada en 1950 por el químico suizo Dr. Henri Martin (Franz et al., 1997), y en 1970 fue evaluada por Monsanto en invernadero, para rápidamente presentarla y comercializarla como el herbicida de marca Roundup (Baird et al., 1971).

Debido a sus propiedades herbicidas no selectivas, en sus inicios el glifosato fue usado solamente para el control de malezas en zonas no agrícolas e industriales, campos en barbecho y bordes de canales y carreteras. Su uso en campos agrícolas fue limitado hasta el desarrollo de la práctica de mínima labranza, donde se aplica glifosato antes de la siembra (Dill et al., 2010); pero su uso se disparó con la introducción, a mediados de los años 90, de los cultivos transgénicos resistentes a glifosato, donde el daño al cultivo por el herbicida no era relevante (Nandula, 2010).

Es el único herbicida en el mercado derivado del aminoácido glicina, que inhibe la enzima 5-enolpyruvylshikimato-3 fosfato sintetasa (EPSPS), necesaria para la biosíntesis de los aminoácidos aromáticos fenilalanina, tirosina y triptófano, requeridos para la síntesis de proteínas, en la vía del shikimato (Jaworski, 1982; Villalba, 2009), ruta metabólica que solo ocurre en plantas, bacterias y hongos. Por esta razón, inicialmente el glifosato fue patentado como un agente antimicrobial (US Patent number 7771736 B2), y se creía que este específico modo de acción contribuía a su baja toxicidad, observada en muchos grupos taxonómicos de organismos no blancos (Dill et al., 2010).

El glifosato es el herbicida no selectivo de mayor uso a nivel mundial (Wakelin et al., 2004); su producción se estimó en $630000 \mathrm{~T}$ para el año 2013. Algunos de los principales productores de glifosato son las industrias BASF SE (Alemania), Bayer Crop Science (Alemania), Monsanto Company (EE.UU.), Nufarm Ltd. (Australia), Syngenta AG (Suiza), Dow AgroSciences LLC 
(EE.UU.), DuPont (EE.UU.), Sino Harvest (China), Zhejiang Xinan Chemical Industrial Group Company, Ltd. (China), Jiangsu Good Harvest-Weien Agrochemical Co. Ltd, (China) y Nantong Jiangshan Agrochemical \& Chemicals Co. Ltd (China) (Markets and Markets, 2015); entre estas, las industrias establecidas en China sintetizan cerca del $80 \%$ de la producción mundial en aproximadamente 200 fábricas con capacidad para producir $720000 \mathrm{~T}$ (Business Wire, 2014).

El glifosato fue clasificado por la Organización Mundial de la Salud (OMS) dentro del grupo IV (en condiciones normales de uso no ofrece peligro) de toxicidad aguda. La Agencia de Protección Ambiental de Estados Unidos (EPA) lo ubica en categoría III (precaución) y algunas formulaciones en categoría I (peligro) y II (advertencia) (WHO-FAO, 1997). Debido a su baja liposolubilidad, el glifosato necesita de coadyuvantes para mejorar su penetración en las plantas u organismos expuestos, lo que aumenta sinérgicamente los efectos del herbicida. Benachour y Séralini (2009) comprobaron que la formulación Roundup ${ }^{\mathrm{R}}$ es al menos dos veces más tóxica que el glifosato y Mesnage et al. (2014), citan que fue 125 veces más tóxica.

Durante muchos años se consideró al glifosato un herbicida de baja toxicidad crónica. Originalmente la EPA lo clasificó en 1985 como posible carcinogénico en humanos (Grupo C), luego cambió esa clasificación en 1991 a "evidencia de ser no carcinogénico" (Grupo E). Recientemente, en marzo de 2015, la Agencia Internacional de Investigación en Cáncer (IARC) lo reclasificó como "probable carcinogénico en humanos" (Grupo 2A); también lo liga con daño en los cromosomas y en el ADN de células humanas (IARC, 2015). Por estas razones se considera un plaguicida altamente peligroso, o HHP por sus siglas en inglés, según la clasificación de la OMS-FAO-PAN (

Otros estudios lo asocian con un aumento en la incidencia del linfoma no Hodgkin (Hardell et al., 2002) y con daño a las células de la placenta humana, aún en dosis diluidas mil veces, lo que puede provocar malformaciones, abortos, problemas hormonales, genitales o de reproducción y distintos tipos de cáncer (Benachour y Séralini, 2009). Otras enfermedades como autismo, Alzheimer y baja movilidad espermática, explicadas por una deficiencia de manganeso $(\mathrm{Mn})$, pueden ser relacionadas a la exposición al herbicida, por las propiedades quelatantes del glifosato que bajan la disponibilidad de $\mathrm{Mn}$ en el organismo. Al contrario, en condiciones adecuadas de Mn en la dieta, el glifosato, al afectar la homeostasis de los ácidos biliares, provoca una acumulación de $\mathrm{Mn}$ en el tronco cerebral, llevando a condiciones como Parkinson y otras enfermedades neurodegenerativas (Samsel y Seneff, 2015).

El glifosato es un herbicida altamente hidrosoluble, con la capacidad de contaminar rápidamente aguas de escorrentía y superficiales como ríos y lagunas; se adsorbe a las partículas del suelo (Santos et al., 2008) y puede, de esta forma, estar biodisponible para organismos que se alimentan por filtración de sedimentos. Es muy tóxico para organismos acuáticos como peces, algas y helechos; medianamente tóxico para anfibios, crustáceos y lombrices de tierra (IRET, 2015).

Esta adsorción a partículas ayuda, en la mayoría de suelos, a que el glifosato no alcance a contaminar las aguas subterráneas; aunque Piccolo y Celano (1994) determinaron que este herbicida puede ser transportado a través del perfil por sustancias húmicas. Esta situación es atenuada por una persistencia menor a 38 días del glifosato en suelos (Giesy et al., 2000).

A pesar de su inactivación en el suelo como herbicida, varios estudios demuestran el impacto que tiene el glifosato en bacterias que participan en el ciclo del nitrógeno, al interferir en los procesos de descomposición de la materia orgánica. El glifosato puede ser exudado por 
raíces y retornar en forma disponible a la solución del suelo (Massenssini et al., 2008), disminuir drásticamente las poblaciones de lombrices de tierra (Eisenia foetida) (Santadino et al., 2014) y aumentar el número de actynomicetes y otros fungi (Araújo et al., 2003; Florida et al., 2012).

Varias especies de artrópodos benéficos, como insectos, arañas, ácaros depredadores de plagas agrícolas y polinizadores, resultan afectadas directamente por la exposición al glifosato e indirectamente por la pérdida de plantas, ya sean malezas que invaden el cultivo o crecen en cercanías donde se refugian y alimentan (Blanco y Leyva, 2010; Mexzón y Chinchilla, 1998; Rojas, 2011).

A pesar de que el glifosato se utiliza más intensivamente en cultivos perennes ya establecidos, con aplicaciones basales dirigidas a las malezas en las entrecalles, es posible causar daños al cultivo por deriva o contacto con follaje bajero. Se puede esperar que hasta un $10 \%$ del herbicida alcance las plantas no blanco de la aplicación, en forma de deriva (Cedergreen, 2008), ya que su potencial de ser absorbido por raíces desde el suelo es despreciable (Giesy et al., 2000) y, debido a la gran capacidad de ser transportado desde las hojas hacia los puntos de crecimiento, puede que cause toxicidad al cultivo (Powles y Wilcut, 2008; Schrubbers et al., 2014).

Otra autora, Cedergreen (2008), concluye que dosis normales producidas por deriva de glifosato pueden estimular el crecimiento en varias especies de plantas hasta por seis semanas después de la exposición, pero seguido se da una depresión en el crecimiento; también esta deriva afecta el desarrollo de semillas (Londo et al., 2014). Los síntomas de fitotoxicidad del glifosato, en dosis normales, aparecen varias semanas después de la aplicación (Shaner, 2010).

En cafetales de Hawaii, Nelson (2008) reporta que el glifosato causa retraso en el crecimiento de los cafetos, amarillamiento del follaje, reducción en la cosecha y predisposición a enfermedades que pueden persistir por varios meses o más de un año, dependiendo de la dosis usada y el área expuesta de la planta. Estos síntomas son similares a los producidos por otros factores de estrés (Schrubbers et al., 2014). Los efectos transitorios pueden resultar en un prolongado e irreversible daño en el desarrollo del cultivo (De Carvalho et al., 2013).

Por otro lado, el continuo uso de glifosato ha provocado la aparición de poblaciones de malezas resistentes. Actualmente se contabilizan 248 biotipos de malezas resistentes a glifosato, pertenecientes a 33 especies en 26 países en todos los continentes (Heap, 2016). En Costa Rica se reportan dos especies resistentes a glifosato Eleusine indica y Paspalum paniculatum, ambas en la zona del Caribe (Valverde, 2010). El objetivo de esta investigación fue estimar el uso reciente (2007 a 2015) que tiene el herbicida glifosato en cultivos y zonas no agrícolas de Costa Rica.

\section{Metodología}

El uso de glifosato en zonas agrícolas y pecuarias se determinó mediante la aplicación de cuestionarios a sujetos productores o encargados de las plantaciones, entre los años 2007 a 2015, como parte del trabajo de diferentes proyectos de investigación (Bravo et al., 2007; Bravo et al., 2012; Bravo et al., 2015; Bravo y Herrera, 2014; Echeverría-Sáenz et al., 2015; Fournier et al., 2010). El instrumento indagó el uso de plaguicidas desde la preparación del terreno hasta poscosecha, en varias fincas por cultivo; las preguntas fueron sobre formulaciones usadas, dosis, frecuencia y métodos de aplicación. El muestreo se realizó en las principales zonas productoras de los cultivos en Costa Rica; la muestra fue diferente en cada cultivo y dependió del área muestreada en cada situación o proyecto (Tabla 1). Para algunos cultivos perennes y forestales (Tabla 2), el uso del glifosato se estimó de acuerdo con el manejo de malezas en cultivos similares. 
ISSN Electrónico: 2215-3470

DOI: http://dx.doi.org/10.15359/ru.31-1.7
UNICIENCIA Vol. 31, No. 1, pp. 59-72. Enero-junio, 2017.

URL: www.revistas.una.ac.cr/uniciencia Email: revistauniciencia@una.cr

Para estimar el uso de glifosato en zonas no agrícolas, se calculó restando a la cantidad importada de glifosato, la cantidad exportada y la usada en los cultivos diagnosticados. Este procedimiento fue usado debido a la falta de datos en el país sobre áreas aplicadas en estas y otras actividades, dosis usadas y frecuencias de aplicación. Esta estimación podría estar subvalorada, ya que las cantidades exportadas podrían proceder del glifosato que ingresa al país bajo la figura de perfeccionamiento activo, lo cual subestima el consumo nacional.

Se consideraron cultivos perennes aquellos cuyo ciclo es mayor a un año y cultivos anuales los que poseen ciclos menores de un año. Algunos cultivos, como piña, plátano y chayote, se pueden manejar de manera anual o bienal, pero se consideraron perennes.

Tabla1

Número de encuestas, área muestreada y año del muestreo por cultivo

\begin{tabular}{lrrc}
\hline $\begin{array}{c}\text { Cultivo } \\
\text { (N. común) }\end{array}$ & Encuestas $\left(\mathbf{n}^{\circ}\right)$ & $\begin{array}{c}\text { Área } \\
\text { (has) }\end{array}$ & $\begin{array}{c}\text { Periodo } \\
\text { (años) }\end{array}$ \\
\hline Arroz & 51 & 15027 & $2010-2013$ \\
Banano & 30 & 6500 & 2014 \\
Café & 36 & 493 & 2014 \\
Caña azúcar & 60 & 18578 & $2010-2012$ \\
Chayote & 25 & 175 & 2007 \\
Cítricos & 4 & 7801 & 2012 \\
Frijol & 6 & 29 & 2013 \\
Maíz & 9 & 228 & $2012-2013$ \\
Ornamentales & 5 & 347 & 2014 \\
Palma aceitera & 14 & 36246 & $2012-2013$ \\
Palmito & 10 & 598 & 2012 \\
Papa & 64 & 123 & $2009-2014$ \\
Papaya & 7 & 43 & $2013-2014$ \\
Pastos & 166 & 10503 & $2009-2014$ \\
Piña & 20 & 5655 & $2007-2014$ \\
Plátano & 30 & 152 & $2007-2014$ \\
Repollo & 18 & 43 & $2009-2014$ \\
Otros tubérculos & 6 & 23 & 2013 \\
Yuca & 6 & 40 & 2013 \\
Zanahoria & 25 & 32 & $2009-2014$ \\
Otras hortalizas & 38 & & $2009-2014$ \\
\hline
\end{tabular}

Nota: Elaboración propia, con base en Bravo et al., 2007; Fournier et al., 2010; Bravo et al., 2012; Bravo y Herrera, 2014; Ramírez et al., 2014a; Ramírez-Muñoz et al., 2014; Bravo et al., 2015; Echeverría-Sáenz et al., 2015. 
UNICIENCIA Vol. 31, No. 1, pp. 59-72. Enero-junio, 2017.

Los datos de uso de glifosato se expresan como el promedio ponderado de uso en kg i.a./ ha/ciclo, ya que las áreas de las fincas son diferentes. Este promedio se calcula multiplicando la cantidad de glifosato aplicada por cada productor (kg i.a./ha) por el área de cada parcela (ha); posteriormente, la sumatoria de las cantidades de glifosato usadas por los productores (kg i.a.) se divide entre el área total del cultivo evaluado. El promedio ponderado da una idea más real de la cantidad de glifosato aplicada en cada hectárea de cultivo por ciclo:

Promedio de uso ponderado $=\sum\left(\mathrm{kg}\right.$ i.a./ha ${ }^{\star}$ área aplicada $) / \sum$ área cultivada

\section{Resultados}

En Costa Rica, la importación y uso de glifosato se inició en el año 1982 con 36 T, se mantuvo con un crecimiento leve hasta finales de los años 90; luego, su importación se incrementó vertiginosamente hasta alcanzar en 2002 las 1337 T y llegar a 1761 T en 2013 (Ramírez et al., 2014a; SFE, 2014) (Figura 1). Casi la totalidad del glifosato que ingresa a Costa Rica bajo la figura de "importación" se consume en el país, pero existe otra cantidad, bajo la figura de "perfeccionamiento activo", que ingresa al país sin pagar impuestos para someterse a un proceso de transformación, ensamblaje o incorporación en conjuntos, para que el bien resultante sea totalmente exportado, o parcialmente consumido en el país pagando los impuestos correspondientes (Procomer, 2015).

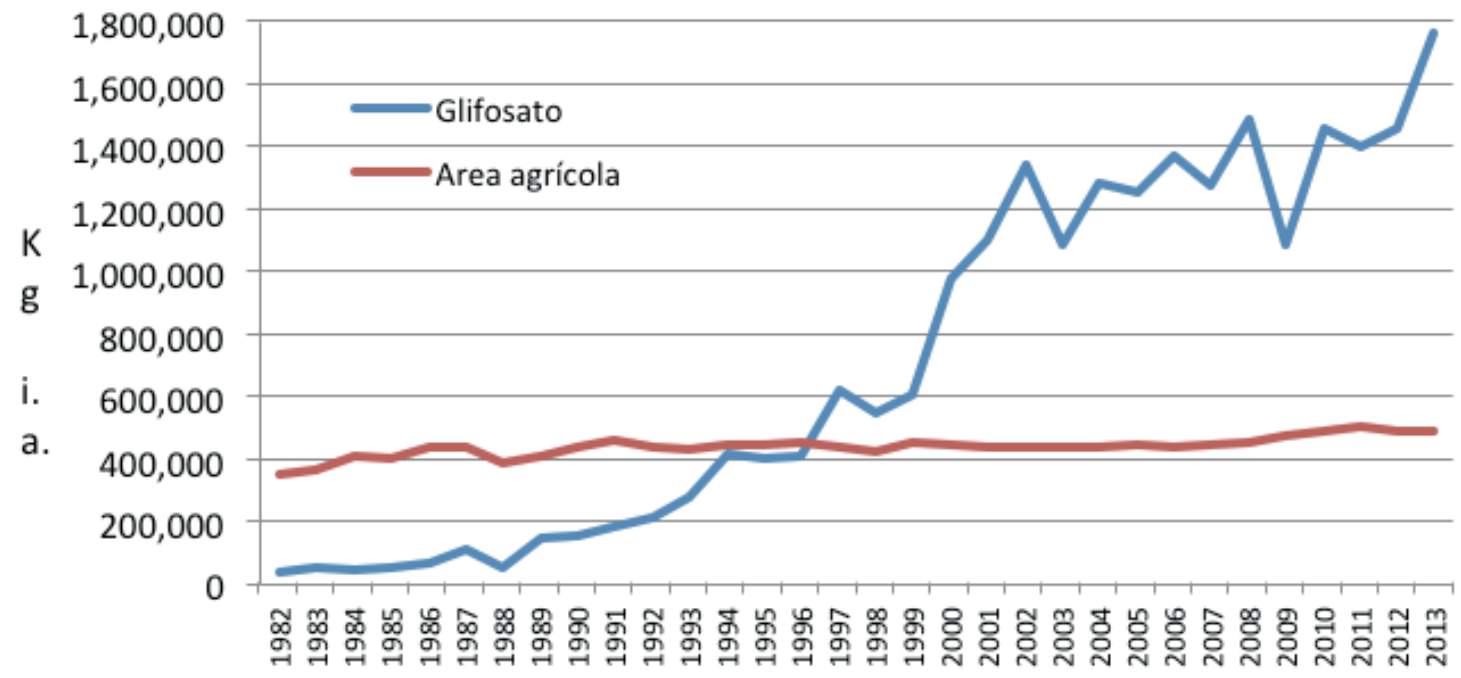

Figura 1. Importación de glifosato (kg i.a.) y área de cultivos anuales y perennes (has). Costa Rica.

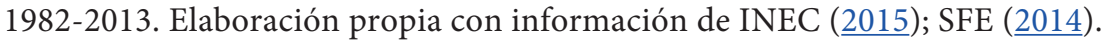

En el mercado existen varias formulaciones químicas de glifosato, dependiendo de la sal que las forma. Una de las primeras en comercializarse fue la sal isopropilamina, actualmente la más utilizada en Costa Rica. Otras son sales de sodio, tetrametilsulfonio (glifosato trimesium), potasio, amonio, monoetanolamina y dimetilamina (Dill et al., 2010). En Costa Rica están registradas, además de formulaciones de sal isopropilamina, formulaciones de glifosato en forma de sal potásica (Touchdown Forte 50 SL) y sal de amonio (Roundup Max 68 WG). En el año 2013 fue cancelado el registro de una formulación de sal tetrametilsulfónica (Touchdown 33 SL) (SFE, 2015). 
Actualmente, debido a la expiración de la patente de Monsanto en el año 2000 (Duke y Powles, 2008), se encuentran registradas en el país para su comercialización en el mercado nacional 74 formulaciones con contenido de glifosato: 94\% con un ingrediente único y 3 en mezcla con otros herbicidas (dos con terbutilazina y una con metsulfuron metilo). Estas formulaciones comerciales contienen glifosato en concentraciones que van desde $20,4 \%$ hasta $76 \%$ de i.a., principalmente al 35,6 y 68\% y formulados como líquidos solubles (SL) y gránulos dispersables (WG), respectivamente (SFE, 2015).

Según el SFE (2015), en Costa Rica existen formulaciones registradas con el ingrediente activo glifosato y, por ende, con uso autorizado, en 32 cultivos agrícolas, además de pastos, plantaciones forestales y áreas no agrícolas. Cultivos perennes como café, palma africana, banano, plátano, caña de azúcar, cacao, cítricos, papaya, mango, macadamia, guanábana, piña, coco y otros frutales tienen registros para uso de glifosato; de la misma forma, cultivos anuales como arroz, papa, melón, maní, frijol, algodón, soya y sorgo. Al contrario, existe una variedad de cultivos donde no se encuentran registradas para su uso formulaciones que contienen glifosato. Estos cultivos son hortalizas como apio, berenjena, cebolla, chile, coliflor, culantro, espinaca, pepino, remolacha, repollo, tomate y vainica; raíces y tubérculos como camote, jengibre, malanga, ñame, ñampí, tiquizque y yuca; frutales como guayaba, granadilla, maracuyá, mora, fresa, palmito, pejibaye y pimienta.

A pesar de lo anterior, el glifosato es el herbicida de mayor uso en el país y el segundo plaguicida más consumido; en el año 2013 se tuvo la importación histórica con $1761417 \mathrm{~kg}$ i.a., y una exportación para ese mismo año de $630164 \mathrm{~kg}$ i.a. (35,8\% de las importaciones del herbicida), representando un consumo en el país de $1131254 \mathrm{~kg}$ i.a. de glifosato (SFE, 2015). Este herbicida tiene un uso generalizado en la agricultura costarricense. Una gran mayoría de los cultivos lo utiliza, ya sea en labores de preparación del terreno (cultivos anuales y perennes) o como controlador de malezas durante el ciclo de los cultivos perennes; además se utiliza en bordes de cultivo, cercas y caminos. También se da un uso en zonas no agrícolas como bordes y líneas de ferrocarril, orillas de carreteras, zonas urbanas, lotes baldíos y hasta en áreas recreativas.

Entre los cultivos donde se utiliza el glifosato para destruir la maleza previo a la preparación del terreno y siembra, están la mayoría de hortalizas, raíces, tubérculos, piña y granos básicos, además de los cultivos perennes. Entre los que se utilizan glifosato con el cultivo presente, se tienen los perennes como café, palma africana, banano, plátano, cítricos, ornamentales de follaje y otros frutales. Por porcentaje de consumo del total nacional, los cultivos perennes son los principales usuarios con $51,6 \%$, le siguen las zonas no agrícolas con $37,1 \%$, los cultivos anuales con $10,8 \%$, de los cuales los granos básicos (arroz, frijol y maíz) representan un 10,1\% y los cultivos bienales (piña, chayote, papaya) con un 1,4\%.

Los cultivos perennes tienen una mayor dependencia del glifosato para sus labores de control de malezas. En el cultivo de palmito, el glifosato representa el $92 \%$ del total de herbicidas, $78 \%$ en cítricos, $76 \%$ en papaya, $69 \%$ en chayote, $67 \%$ en palma y $64 \%$ en banano y plátano. Dentro de los cultivos anuales, $48 \%$ en frijol, $29 \%$ en arroz, $26 \%$ en raíces y tubérculos y $23 \%$ en hortalizas. Con respecto al peso que tiene el glifosato en el total de uso de plaguicidas por cultivo, se tiene que en palmito representa $92 \%, 64 \%$ en palma y forestales, $51 \%$ en cítricos, $17 \%$ en café, $10 \%$ en plátano y $2 \%$ en banano; de la misma forma, 19\% en arroz, $18 \%$ en raíces y tubérculos, $16 \%$ en frijol y menos del $1 \%$ en algunas hortalizas y piña. 
El cultivo que más glifosato consume porcentualmente, de acuerdo con el uso total en Costa Rica, es la palma africana (24,9\%), le sigue arroz (7,8\%), café $(5,4 \%)$, banano $(5,2 \%)$, cítricos $(4,6 \%)$, pastos $(3,7 \%)$ y frijol (2\%). Para otros cultivos perennes como mango, aguacate, mora, rambután, cacao, etc., se estimó un uso en conjunto del 1,1\%. Tubérculos como yuca, tiquizque, ñame, ñampí y otros suman un uso del $0,4 \%$ y las hortalizas que incluyen papa, zanahoria, repollo, cebolla, chile, tomate junto con melón y sandía suman el 0,4\% (Tabla 2).

Se estimó un consumo para zonas no agrícolas y urbanas cercano al 37,1\% del total de glifosato usado en Costa Rica. Para mantener las vías férreas libres de maleza, el Instituto Costarricense de Ferrocarriles (Incofer) en el año 2014 utilizó cerca de $1800 \mathrm{~kg}$ glifosato en 340 kilómetros de líneas, con aplicaciones entre 4 a 6 veces por año (Albin Quirós, Incofer. Comunicación personal). La Refinadora Costarricense de Petróleo (RECOPE) en 2014 utilizó $430 \mathrm{~kg}$ de una formulación con $68 \%$ de glifosato para mantener libres de malezas los bordes de los poliductos que suman cerca de 153 hectáreas, correspondiente a 1,91 kg i.a./ha/año (José D. Mora S. Contratista Recope. Comunicación personal). En observaciones personales, se ha constatado que algunas municipalidades usan glifosato para la limpieza de vías, aceras, caños, entre otras zonas y que muchos particulares mantienen libre de malezas sus lotes baldíos con glifosato.

A pesar de que el glifosato no posee selectividad, en cultivos perennes su uso se vuelve selectivo por aplicación, ya que es asperjado varias veces por ciclo para controlar las malezas que crecen bajo los árboles o palmas, tanto en la entrecalle como en la ronda, evitando la aplicación directa en los cultivos y su afectación. Por este motivo, los cultivos perennes son mayores usuarios de glifosato que los cultivos anuales.

Como se observa en la tabla 2, algunos cultivos perennes como pejibaye para palmito, cítricos y palma africana, de ciclo más extenso, tienen un uso de glifosato por arriba de $2,74 \mathrm{~kg}$ i.a./ha/año. Incluso, la palma africana tiene un valor de $4,24 \mathrm{~kg}$ i.a./ha/año, lo que corresponde a una aplicación anual de casi 12 litros/ha/año de una formulación comercial al 35,6\% i.a., o 6,2 kilogramos de una formulación al 68\%, ambas las más utilizadas en nuestro país. En este cultivo, el glifosato se usa principalmente en plantaciones mayores a 5 años, para evitar daños por deriva en palmas con hojas bajeras. En plantas ornamentales perennes, el uso es de 0,85 kg i.a./ha/año.

En café, el uso de glifosato es relativamente bajo, al compararlo con otros cultivos perennes, debido principalmente a la alta cobertura del cultivo que reduce el crecimiento de malezas, aunado a los árboles de sombra utilizados en los cafetales y recientemente por la fitotoxicidad notada en su producción, lo que ha llevado a reemplazarlo por controles manuales o por otros herbicidas como paraquat, diquat o glufosinato de amonio. Era común en la década anterior, el uso de paraquat o glifosato en aplicaciones solas o en mezcla con herbicidas de efecto residual como terbutilazina y oxifluorfen (Gómez, 2005). Para 1998, Chaverri et al. (2000) reportaron un uso de glifosato en café de 0,9 kg i.a./ha/año y Bravo et al. (2013) para la zona de Los Santos en 2004, un uso de 0,82 kg i.a./ha/año, muy cercanos al valor de 0,72 encontrado en 2014.

Actualmente, el uso de glifosato en caña de azúcar es de $0,15 \mathrm{~kg}$ i.a./ha/año, muy cercano a lo reportado por Bravo et al. (2013), de 0,28 kg i.a./ha/año para el año 2010 para la Península de Nicoya. En este cultivo, el glifosato se utiliza como herbicida presiembra y en bordes; también como madurante aplicado 7 a 8 semanas antes de la cosecha, en ciertas áreas y en dosis bajas de 0,3 a $0,6 \mathrm{~kg}$ i.a./ha. De la misma forma, algunos sujetos productores de maíz lo utilizan antes de la cosecha del grano como un tipo de desecante. 
ISSN Electrónico: 2215-3470

DOI: http://dx.doi.org/10.15359/ru.31-1.7
UNICIENCIA Vol. 31, No. 1, pp. 59-72. Enero-junio, 2017.

URL: www.revistas.una.ac.cr/uniciencia Email: revistauniciencia@una.cr

Tabla 2

Uso de glifosato por cultivo, área cultivada, consumo anual y porcentual. Costa Rica. Estimación para 2013 - 2015

\begin{tabular}{|c|c|c|c|c|c|c|}
\hline $\begin{array}{l}\text { Cultivo } \\
\text { (N. común) }\end{array}$ & $\begin{array}{c}\text { Uso } \\
\text { (kgi.a./ha/año) }\end{array}$ & $\begin{array}{l}\% \text { del total de } \\
\text { plaguicidas }\end{array}$ & $\begin{array}{c}\% \text { del total de } \\
\text { herbicidas }\end{array}$ & $\begin{array}{l}\text { Área } \\
\text { (has) }\end{array}$ & $\begin{array}{c}\text { Consumo } \\
\text { (kg i.a./año) }\end{array}$ & $\begin{array}{l}\% \text { del total } \\
\text { importado }\end{array}$ \\
\hline Arroz & 1,51 & 19,00 & 29,40 & 58540 & 88395 & 7,81 \\
\hline Banano & 1,14 & 1,60 & 64,00 & 51758 & 59004 & 5,22 \\
\hline Café & 0,72 & 17,10 & 48,90 & 84133 & 60576 & 5,36 \\
\hline Caña de azúcar & 0,15 & 1,72 & 1,73 & 65062 & 9759 & 0,86 \\
\hline Chayote & 0,59 & 9,60 & 69,00 & 480 & 283 & 0,03 \\
\hline Cítricos & 2,68 & 51,10 & 77,50 & 19596 & 52517 & 4,64 \\
\hline Frijol & 1,14 & 16,30 & 48,30 & 19471 & 22197 & 1,96 \\
\hline Maíz & 0,23 & 7,90 & 10,60 & 15769 & 3627 & 0,32 \\
\hline Ornamentales & 0,85 & 5,00 & 27,80 & 6215 & 5283 & 0,47 \\
\hline Palma africana & 4,24 & 64,00 & 66,60 & 66420 & 281621 & 24,90 \\
\hline Palmito & 2,74 & 92,40 & 92,40 & 4618 & 12653 & 1,12 \\
\hline Papa & 0,12 & 0,30 & 13,80 & 3747 & 1162 & 0,04 \\
\hline Papaya & 2,01 & 9,00 & 75,60 & 1394 & 2802 & 0,25 \\
\hline Pastos & 0,04 & 12,90 & 17,40 & 1044910 & 41796 & 3,70 \\
\hline Piña & 0,34 & 0,75 & 3,93 & 37660 & 12804 & 1,13 \\
\hline Plátano & 1,65 & 10,10 & 64,50 & 10015 & 16525 & 1,46 \\
\hline Repollo & 0,63 & 4,50 & 37,50 & 820 & 517 & 0,05 \\
\hline Yuca & 0,18 & 5,50 & 8,30 & 15045 & 2708 & 0,24 \\
\hline Zanahoria & 0,83 & 5,20 & 7,00 & 1140 & 946 & 0,08 \\
\hline $\begin{array}{l}\text { Otras hortalizas } \\
\text { y frutas* }\end{array}$ & 0,09 & 0,01 & 23,10 & 15037 & 1353 & 0,12 \\
\hline Otros perennes & 0,80 & 18,60 & 64,00 & 15213 & 12170 & 1,08 \\
\hline $\begin{array}{l}\text { Otros } \\
\text { tubérculos }\end{array}$ & 0,18 & 18,30 & 26,00 & 7176 & 1292 & 0,11 \\
\hline Forestales & 0,36 & 64,00 & 66,00 & 60169 & 21661 & 1,92 \\
\hline $\begin{array}{l}\text { Zonas no } \\
\text { agrícolas }\end{array}$ & & & & & & 37,12 \\
\hline $\begin{array}{l}\text { Importación } \\
\text { (kg i.a.) }\end{array}$ & & & & & 1131254 & 100,00 \\
\hline
\end{tabular}

Nota: ${ }^{*}$ cebolla, brócoli, coliflor, culantro, remolacha, chile, tomate, lechuga, melón y sandía. ${ }^{* *}$ mango, cacao, aguacate, mora, rambután, coco, manzana y otros. ${ }^{* \star \star}$ ñame, tiquizque, ñampí, jengibre y otros. Elaboración propiacon base en Bravo et al., 2007; Fournier et al., 2010; Bravo et al., 2012; Bravo y Herrera, 2014; Ramírez et al., 2014a; Ramírez et al., 2014b; Ramírez-Muñoz et al., 2014; Bravo et al., 2015; INEC, 2015; SFE, 2014. 
UNICIENCIA Vol. 31, No. 1, pp. 59-72. Enero-junio, 2017.

ISSN Electrónico: 2215-3470

URL: www.revistas.una.ac.cr/uniciencia

DOI: http://dx.doi.org/10.15359/ru.31-1.7

En el cultivo de banano, el glifosato es proporcionalmente el herbicida de mayor uso. Se estimó en $1,14 \mathrm{~kg}$ i.a./ha/año de promedio ponderado (64\% de los herbicidas). Chaverri et al., (2000) reportaron un uso de glifosato en banano de $0,75 \mathrm{~kg}$ i.a./ha/año para el año 1993 y de 2,11 kg i.a./ha/año en el periodo 1998-1999, para la zona de Pococí y Limón, respectivamente. Bravo et al. (2013) reportaron, para la provincia de Limón, un uso de glifosato en banano de 2,34 $\mathrm{kg}$ i.a./ha/año para el año 2006. Esta reducción puede deberse principalmente al uso de prácticas de control mecánico, al uso de coberturas vivas y muertas para control de malezas y al uso de mejores tecnologías de aplicación.

En cultivos de ciclo corto o manejados como anuales, el glifosato se utiliza principalmente para eliminar malezas antes de la preparación del suelo. Es así como en la mayoría de hortalizas se aplica exclusivamente antes de la siembra y su uso con cultivo presente es muy raro, debido a la probabilidad de tener daños graves por deriva. Para la zona de Zarcero en Alajuela, en 2014 se tiene un uso de glifosato en papa de $0,12 \mathrm{~kg}$ i.a./ha/ciclo, en zanahoria de 0,83 , en repollo de 0,63 , en culantro de 0,18, en pastos de 0,09 y en remolacha de 0,07 (Ramírez et al., 2014b). Para otra zona hortícola, Pacayas, Cartago, durante el periodo 2006 a 2009, se obtuvieron valores de uso de glifosato en papa de 0,31 kg i.a./ha/ciclo (Ramírez-Muñoz et al., 2014).

En el cultivo de arroz, sobre todo en lotes con infestaciones de arroces voluntarios, arroz rojo o arroz maleza, el glifosato se utiliza, una o más veces antes de la siembra, para agotar el banco de semillas del suelo. Así mismo, se utiliza mediante la técnica de mínima labranza, al aplicarlo al barbecho recién cosechado y proceder a la siembra de arroz, sin mayor disturbación mecánica del suelo. Debido a esto, el uso de glifosato en arroz, comparado con otros cultivos anuales, es relativamente elevado, con promedio ponderado de 1,59 kg i.a./ha/ciclo.

\section{Conclusiones}

Tomando en cuenta la distribución espacial de los cultivos y las zonas no agrícolas donde se utiliza glifosato, se puede decir que la mayoría del territorio nacional está expuesto a este herbicida. Del glifosato usado en Costa Rica, la mitad lo consumen los cultivos perennes, más de una tercera parte se consume en zonas no agrícolas y solamente un $10 \%$ en cultivos anuales.

En varios cultivos perennes, los mayores usuarios de glifosato en Costa Rica, los daños por fitotoxicidad al cultivo han ocasionado que sectores productores, especialmente cafetaleros y bananeros, disminuyan las aplicaciones de glifosato y se apoyen más en formas no químicas de control de malezas, como manejo mecánico y con coberturas vegetales. La adopción de una certificación de mercado internacional ha ayudado en esta reducción.

En algunas fincas, especialmente en cultivos perennes como pejibaye para palmito o banano, el manejo de malezas se ha basado en el control químico utilizando al glifosato como único herbicida aplicado. Algunas certificaciones de mercado internacional han hecho que se dejen de usar ciertos herbicidas, lo que ha reducido las opciones para variarlos. En esta situación, sumadas la poca labranza del suelo, carencia de rotación de cultivos y de métodos de control de malezas, resultan en una intensa presión, la cual puede acelerar la evolución de malezas resistentes al herbicida (Dinelli et al., 2008).

Considerando las grandes extensiones de cultivos y zonas no agrícolas tratadas con glifosato anualmente, es probable que también los organismos que no son el blanco estén siendo afectados. Sería oportuno realizar estudios al respecto, no solamente de los efectos agudos, sino 
ISSN Electrónico: 2215-3470

DOI: http://dx.doi.org/10.15359/ru.31-1.7
UNICIENCIA Vol. 31, No. 1, pp. 59-72. Enero-junio, 2017.

URL: www.revistas.una.ac.cr/uniciencia Email: revistauniciencia@una.cr

también de las consecuencias que produce este herbicida por exposiciones subletales. De igual forma, estudiar los resultados colaterales del glifosato en la aparición y resurgencia de ciertas enfermedades en algunos cultivos.

Se hace necesaria la adopción de formas más sustentables de manejo y control de malezas, con formas que excluyan el uso de este tipo de plaguicidas de comprobada toxicidad a largo plazo para los seres humanos y causantes de daños al ambiente, de manera que comprometen la calidad y disponibilidad de recursos para las generaciones futuras.

\section{Referencias}

Araújo, A. S. F., Monteiro, R. T. R. y Abarkeli, R. B. (2003). Effect of glyphosate on the microbial activity of two Brazilians soils. Revista Chemosphere, 52, 799-357.

Baird, D. D., Upchurchu, R. P., Homesley, W. B. y Franz, J. E. (1971). Introduction of a new broad spectrum post emergence herbicide class with utility for herbaceous perennial weed control. North Central Weed Science Society, 26, 64-68.

Benachour, N. y Séralini, G. E. (2009). Glyphosate formulations induce apoptosis and necrosis in human umbilical, embryonic, and placental cells. Chem. Res. Toxicol, 22(1), 97-105.

Blanco, Y. y Leyva, A. (2010). Abundancia y diversidad de especies de arvenses en el cultivo del maíz (Zea mays, L.) precedido de un barbecho transitorio después de la papa. Cultivos tropicales, 30(1), 11-17.

Bravo V., Partanen, T. y Wesseling, C. (2007). Indicadores de riesgo para la salud humana en la sostenibilidad de cadenas agro-alimentarias. Informe Final Proyecto Mejoramiento de la Sostenibilidad de Cadenas Agroalimentarias en América Central. Universidad Nacional. Facultad de Ciencias de la Tierra y el Mar. Instituto Regional de Estudios en Sustancias Tóxicas (IRET). Costa Rica.

Bravo, V., de la Cruz, E., Herrera, G., Moraga, G., Ramírez, F., Ruepert, C., Morera, M., Solano, K., Pinnock, M y Rodríguez, R. (2012). Vigilancia del uso de plaguicidas en actividades agropecuarias, con énfasis en el herbicida 2,4-D, por peligro de contaminación de aguas subterráneas y superficiales en la Península de Nicoya, Guanacaste. Informe final de proyecto 022216-00. Instituto Regional de Estudios en Sustancias Tóxicas. Facultad de Tierra y Mar. Universidad Nacional. Heredia, Costa Rica.

Bravo, V., de la Cruz, E., Herrera, G. y Ramírez, F. (2013). Uso de plaguicidas en cultivos agrícolas como herramienta para el monitoreo de peligros en salud. Uniciencia, 27(1), 351-376.

Bravo, V. y Herrera, G. (2014). Diagnóstico de importación, uso y caracterización de sustancias tóxicas, principalmente plaguicidas, para el soporte de las actividades permanentes de investigación, extensión $y$ docencia del Instituto Regional de Estudios en Sustancias Tóxicas. Informe de Avance de Primer Año. Instituto Regional de Estudios en Sustancias Tóxicas. Facultad de Tierra y Mar. Universidad Nacional. Heredia, Costa Rica.

Bravo, V., Berrocal, S., Ramírez, F., de la Cruz, E., Canto, N., Tatis, A., Mejía, W. y Rodríguez, T. (2015). Importación de plaguicidas y peligros en salud en América Central durante el periodo 2005 - 2009. Uniciencia, 29(2), 84-106.

Business Wire. (2014). Research and Markets: China Glyphosate Market Research and Development Forecasts Report 2014. Recuperado de: http://www.businesswire.com/news/home/20141114005468/ en/Research-Markets-China-Glyphosate-Market-Research-Development\#.VT DS B5tOE

Cedergreen, N. (2008). Is the growth stimulation by low doses of glyphosate sustained over time? Environmental Pollution, 156, 1099-1104.

Chaverri, F., Soto, L., Ramírez, F. y Bravo, V. (2000). Diagnóstico preliminar del uso de plaguicidas en los cultivos de arroz, banano, caña de azúcar, café, cebolla, melón, naranja, papa, piña, tomate, flores y plantas ornamentales. Informe Preliminar. Instituto Regional de Estudios en Sustancias Tóxicas. Facultad de Tierra y Mar. Universidad Nacional. Heredia, Costa Rica. 
UNICIENCIA Vol. 31, No. 1, pp. 59-72. Enero-junio, 2017.

ISSN Electrónico: 2215-3470

URL: www.revistas.una.ac.cr/uniciencia

DOI: $\underline{\text { http://dx.doi.org/10.15359/ru.31-1.7 }}$

De Carvalho, F., Franca, A., Lemos, V., Ferreira, E., Dos Santos, J. y Da Silva, A. (2013). Photosynthetic activity of coffee after application of glyphosate subdoses. Acta Scientiarum: Agronomy, 35(1), 109-115.

Dill, G., Sammons, D., Feng, P., Kohn, F., Kretzmer, K., Mehrsheikh, A., Bleeke, M., Honegger, J., Farmer, D., Wright, D. y Haupfear, E. (2010). Glyphosate Resistance in Crops and Weeds, History, Development and Management. Hoboken. In Nandula, V. K. (Ed.), Glyphosate Resistance in Crops and Weeds: History, Development, and Management (pp. 1-33). Hoboken, New Jersey: John Wiley and Sons.

Dinelli, G., Marotti, I., Bonetti, A., Catizone, P., Urbano, J., y Barnes, J. (2008). Physiological and molecular bases of glyphosate resistance in Conyza bonariensis biotypes from Spain. Weed Research, 48, 257-265.

Duke, S. y Powles, S. (2008). Glyphosate: a once-in-a-century herbicide. Pest Management Science, 64, 319-325.

Echeverría-Sáenz, S., Pinnock, M., de la Cruz, E., Bravo, V., Herrera, G., Ugalde, R., Vargas, S., Ruepert, C., Moraga, G. y Mallenco, R. (2015). Informe final integrado. Estudio de la contaminación y ecotoxicología en el río Parismina. Instituto Regional de Estudios en Sustancias Tóxicas. Facultad de Ciencias de la Tierra y el Mar. Universidad Nacional. Heredia, Costa Rica.

FAOSTAT. (2015). Active ingredient use in arable lands and permanent crops. Costa Rica 2010. Statistic Division. Recuperado de: http://faostat3.fao.org/download/E/EP/E

Florida, N., López, C. y Pocomucha, V. (2012). Efecto del herbicida paraquat y glifosato en propiedades del suelo que condicionan el desarrollo de bacterias y fungi. Investigación y Amazonía, 2(1-2), 35-43.

Fournier, M. L., Ramírez, F., Ruepert C., Vargas, S. y Echeverría, S. (2010). Diagnóstico sobre contaminación de aguas, suelos y productos hortícolas por el uso de agroquímicos en la microcuenca de las quebradas Plantón y Pacayas en Cartago, Costa Rica. Prestación de Servicios entre el Instituto Nacional de Innovación y Transferencia en Tecnología Agropecuaria (INTA) y la Universidad Nacional.

Franz, J. E., Mao, M. K. y Sikorski, J. A. (1997). Glyphosate: A Unique Global Pesticide. Washingtong, D.C. ACS Monografía 189. American Chemical Society, pp. 163-175

Giesy, J. P., Dobson, S. y Solomon, K. R. (2000). Ecotoxicological risk assessment for Roundup herbicide. Reviews of Environmental Contamination and Toxicology, 167, 35-120.

Gómez, R. (2005). Efecto del control de malezas con paraquat y glifosato sobre la erosión y pérdida de nutrimentos del suelo en cafeto. Agronomía Mesoamericana, 16(1), 77-87.

Hardell, L., Eriksson, M. y Nordstrom, M. (2002). Exposure to Pesticides as Risk Factor for NonHodgkin's Lymphoma and Hairy Cell Leukemia: Pooled Analysis of Two Swedish Case-control Studies. Leukemia \& Lymphoma, 43(5), 1043-1049.

Heap, I. (2016). Glycines Resistant Weeds. International Survey of Resistant Weeds. Recuperado de http:// www.weedscience.org/Summary/UspeciesMOA.asp?lstMOAID $=12$

International Agency for Research on Cancer (IARC). (2015). IARCMonographs Volume 112: evaluation of five organophosphate insecticides and herbicides. Recuperado de http://www.iarc.fr/en/mediacentre/ iarcnews/pdf/MonographVolume112.pdf

Instituto Nacional de Estadística y Censos (INEC). (2015). VI Censo Nacional Agropecuario. Resultados Generales. San José, Costa Rica. Recuperado de http://www.inec.go.cr/wwwisis/documentos/INEC/ Censos/2014\%20-\%20Censo\%20Nacional\%20Agropecuario/Resultados_Generales/Resultados Generales_CENAGRO_2014.pdf 
Instituto Regional de Estudios en Sustancias Tóxicas (IRET). (2015). Base de datos de ingredientes activos importados en Centroamérica. Universidad Nacional. Costa Rica. Recuperado de http://www. plaguicidasdecentroamerica.info/index.php/base-de-datos/ingredientes-activos/306-glifosato.

Jaworski, E. G. (1982). Mode of action of N-phosphonomethyl glycine: inhibition of aromatic amino acid biosynthesis. J. Agric. Food Chemistry, 20, 176-193.

Londo, J., McKinney, J., Schwartz, M., Bollman, M., Sagers, C. y Watrud, L. (2014). Sub-lethal glyphosate exposure alters flowering phenology and causes transient male-sterilioty in Brassica spp. Plant Biology, 14(1), 1-21.

Markets and Markets. (2015). Glyphosate Market, by Application (Genetically Modified Crops and Conventional Crops) \& by Region - Global Trends \& Forecasts To 2019. Recuperado de http://www.marketsandmarkets. com/Market-Reports/glyphosate-market-8522593.html?gclid=CO2ZmobCmcUCFWlo7Aodm1QAdQ

Massenssini, A. M., Costa, M .D., Reis, M. R. y Silva, A. A. (2008). Atividade de isolados bacterianos solubilizadores de fosfato na presence de formulacoes comerciais de Glyphosate. Planta Daninha, 26(4).

Mesnage, R., Defarge, N., de Vendomois, J. S. y Séralini, G. E. (2014). Major pesticides are more toxic to humans cells tan either declared active principles. Biomed Research International, 10, 1155-179691.

Mexzón, R. y Chinchilla, C. (1998). Especies vegetales atrayentes de la entomofauna benéfica en plantaciones de palma aceitera (Elaeis guineensis Jacq.). ASD (Semillas y clones de palma aceitera de alto rendimiento. Recuperado de www.asd-cr.com

Nandula, V.K. (2010). Herbicide resistance: definitions and concepts. In Nandula, V. K. (Ed.), Glyphosate Resistance in Crops and Weeds: History, Development, and Management (pp. 35-43). Hoboken, New Jersey: John Wiley and Sons.

Nelson, S. (2008). Glyphosate herbicide injury to coffee. Crop Extension Service, CTAHR, University of Hawaii. Plant Disease, 2008.

Pesticide Action Network(PAN).(2015).PANInternational List of HighlyHazardous Pesticides. Recuperado de http://www.panna.org/issues/publication/pan-international-list-highly-hazardous-pesticides

Piccolo, A. J. y Celano, G. (1994). Hydrogen bonding interactions between the herbicide glyphosate and water-soluble humic substances. Environmental Toxicology and Chemistry 13, 1737-1741.

Powles, S. B. y Wilcut, J. (2008). Review of evolved glyphosate-resistant weeds around the world: lessons to be learnt. Pest Manag Sci, 64, 360-365.

Promotora del Comercio Exterior de Costa Rica (Procomer). (2015). Régimen de perfeccionamiento activo. Recuperado de http://www.procomer.com/content/perfeccionamiento-activo-3.html.

Ramírez, F., Chaverri, F., de la Cruz, E., Wesseling, C., Castillo, L., Bravo, V. (2009). Importación de plaguicidas en Costa Rica, periodo 1977-2006. En Serie Informes Técnicos. Instituto Regional de Estudios en Sustancias Tóxicas, Universidad Nacional de Costa Rica, 6, 58.

Ramírez-Muñoz, F., Fournier-Leiva, M. L., Ruepert, C. e Hidalgo-Ardón, C. (2014). Uso de agroquímicos en el cultivo de papa en Pacayas, Cartago, Costa Rica. Agron. Mesoam, 25(2), 337-345.

Ramírez, F., de la Cruz, E., Berrocal, S. y Bravo, V. (2014a). Importación de plaguicidas por habitante total, habitante rural, trabajador agrícola y área agrícola como herramienta para el monitoreo de peligros en la salud y el ambiente. Costa Rica, 2000-2012. Costa Rica: Artículo divulgativo del Instituto Regional de Estudios en Sustancias Tóxicas en página en internet del Observatorio Ambiental de la Universidad Nacional. Recuperado de http://www.una.ac.cr/observatorio ambiental

Ramírez, F., Chaverri, F., Fournier, M. L., de la Cruz, E., Bravo, V., Echeverría, S., Moraga, G., Ruepert, C., Berrocal, S., Alfaro, A. y Pinnock, M. (2014b). Las buenas prácticas agrícolas en el uso y manejo de agroquímicos en la zona hortícola de Zarcero, Alajuela. Informe de Avance de Primer Año. Instituto Regional de Estudios en Sustancias Tóxicas. Facultad de Tierra y Mar. Universidad Nacional. Heredia, Costa Rica. 
UNICIENCIA Vol. 31, No. 1, pp. 59-72. Enero-junio, 2017.

ISSN Electrónico: 2215-3470

URL: www.revistas.una.ac.cr/uniciencia

DOI: $\underline{\text { http://dx.doi.org/10.15359/ru.31-1.7 }}$

Email: revistauniciencia@una.cr

Rojas, C. (2011). Prospección de la entomofauna benéfica asociada al cultivo del banano (Musa AAA), subgrupo "Cavendish", en la Región Atlántica de Costa Rica (Tesis de licenciatura). Instituto Tecnológico de Costa Rica, Escuela de Agronomía, San Carlos, Alajuela, Costa Rica.

Samsel, A. y Seneff, S. (2015). Glyphosate, pathways to modern diseases III: Manganese, neurological diseases, and associated pathologies. Surgical Neurology International, 6-45

Santadino, M., Coviella, C. y Momo, F. (2014). Glyphosate sublethal effects on the populations dynamics of the earthworm Eisenia fetida (Savigny, 1826). Water Air Soil Pollut, 225-2207

Santos, L. D., Santos, J. B., Ferreira, F. A., Oliveira, J. A., Bentivenha, S., Machado, A. F. L. (2008). Exsudacao radicular de glyphosate por Brachairia decumbens e seus efeitos em plantas de eucalipto. Planta Daninha, 26(2).

Schrubers, L., Valverde, B., Sorensen, J. y Cedergreen, N. (2014). Glyphosate spray drift in Coffea arabica - Sensitivity of coffee plants and possible use of shikimic acid as a biomarker for glyphosate exposure. Pesticide Biochemistry and Physiology, 115, 15-22.

SFE. (2014). Importación de plaguicidas en Costa Rica. Recuperado de https://www.sfe.go.cr/perfiles/ importacion/importacion agroquimicos equipos.html

SFE. (2015). Centro de Consulta de Insumos. Recuperado de https://www.sfe.go.cr/insumosys/Principal. html

Shaner, D. (2010). Testing Methods for Glyphosate Resistance. In Nandula, V. K. (Ed.), Glyphosate Resistance in Crops and Weeds, History, Development and Management (pp. 93-118). Hoboken, New Jersey: John Wiley and Sons.

Valverde, B. E. (2010). Glyphosate Resistance in Latin America. In Nandula, V. K. (Ed.), Glyphosate Resistance in Crops and Weeds, History, Development and Management (pp. 249-280). Hoboken, New Jersey: John Wiley and Sons.

Villalba, A. (2009). Resistencia a herbicidas; Glifosato. Ciencia, Docencia y Tecnología, 39, 169-186. Santa $\mathrm{Fe}$, Argentina.

Wakelin, A. M., Lorraine, D. F. y Preston, C. (2004). Glyphosate resistance in four different populations of Lolium rigidum is associated with reduce traslocation of glyphosate to meristematic zones. Weed Resistance, 44, 453-459.

World Health Organisation (WHO) y Food and Agriculture Organization of the United Nations (FAO). (1997). Glyphosate, WHO/FAO Data Sheets on Pesticides No. 91, WHO/PCS/DS/96.91. Recuperado de http://www.inchem.org/documents/pds/pds/pest91_e.htm

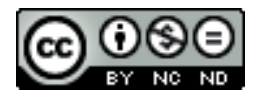

Uso del herbicida glifosato en Costa Rica en el periodo 2007 a 2015 (Fernando Ramírez-Muñoz y otros) por Revista $\underline{\text { Uniciencia se encuentra bajo una Licencia CreativeCommons Atribución-NoComercial-SinDerivadas 3.0 Unported. }}$ 